\title{
Digital model of sharing economy: blockchain technology management ${ }^{a}$
}

\author{
Alexander Babkin ${ }^{*}$, Tatiana Golovina ${ }^{3}$, Andrey Polyanin ${ }^{3}$, and Yuliya Vertakova $^{2}$, \\ ${ }^{1}$ Peter the Great St. Petersburg Polytechnic University, 195251, Politekhnicheskaya st., 29, Russian \\ Federation \\ ${ }^{2}$ Southwest State University, Kursk, 50 let Oktyabrya, 94, Russian Federation \\ ${ }^{3}$ Mid-Russian Management Institute - branch of RANEPA, 302028, Orel, Pobedy Boulevard, 5a, \\ Russian Federation
}

\begin{abstract}
The modernization of traditional process and service industries, organization of trading and procurement procedures, related financial and logistical operations, change in the structure of consumption associated with the through penetration of information technologies and digitization of economic processes creates the basis for formation of new markets and conditions for their functioning. As employees, consumers, businesses, and manufacturing processes become increasingly related as a single digital space, digitalization offers wide possibilities for new decision-making models being the basis for ongoing global economic and social transformations which change business and consumer models, one of which is the sharing economy. The digital model of sharing economy will be developed and transformed in the next few years to achieve the main purpose - the use of unengaged or underused assets in the economy. In this regard, the search for new tools and technologies for business models development is vital. The authors present the content, advantages, current state and prospects for development of the distributed registry technology (blockchain). It is presented that it will increase transparency, security and efficiency of transactions of economic entities in various financial and nonfinancial fields. A transactional model of the economic system based on the blockchain technology is presented. The sharing economy features and characteristics are given.
\end{abstract}

\section{Introduction}

The modern economy is post-industrial, and it is often called a new, innovative economy of knowledge, competences, networking. It should be noted that this list of definitions on the one hand brings a different meaning, and on the other hand it characterizes the same period of economic activity. Recently, the digital economy concept has appeared both in the economic theory and in the practical activities of a number of countries. This is due to the

\footnotetext{
*Corresponding author: al-vas@mail.ru

a This paper was prepared in the studies for RFBR project No. 18-010-01119 "Management of digital transformation of innovation-industrial cluster as a strategic element of the industrial digital platform: methodology, tools, practice".
} 
fact that the beginning of the XXI century provided the development of digital technologies based on the information revolution and the processes of economy globalization. The society and economy management processes information has become the main resource. In the person's hands, it is transformed into knowledge, and socioeconomic relations are increasingly transferred to the network space. The key factor of digital transformation in the activity of market entity is the digital culture development.

Currently, the digital economy is included in the list of the main aspects of the strategic development in Russia and many foreign countries. The task for creating the conditions for deep system digitalization of the life style and economic structure in Russia [1, 2], China [3], the EAEU countries [4], Japan [5] and other foreign countries is specified at the government levels. The digital economy development can affect the internal and external business environment, the patterns of its behavior including using the technology to maintain the distributed registry or blockchain technology. The blockchain is a technology that is at the top of the entire digital economy. In the blockchain there are several very important innovations - assets decentralization and tokenization. However, today it is still difficult to implement such models in practice. In any case, the technology itself, which allows us to build up blockchains, has not yet reached the required level of maturity and continues its development.

Up-to-date scientists and practitioners have not formed a common opinion on the content of the digital model of sharing economy: some consider it as an effective platform for transactions within a network that combines equal participants, while others see it as a source of corruption and shadow money flows, and other negative events which put the brakes on the economic growth. However, none of the economists will deny that the sharing economy has great prospects and already has a significant impact on the global economic processes.

With the development of the digitalization processes, the interest in studying the sharing economy only increases. The fact is that many economists, as one of the digital economy characteristics, call its distribution in the world. The following scientists made the particular contribution to the study of the sharing economy theory and its role in the modern ecosystem: Don Tapscott [6], A. Stephany [7], M. Vidas-Bubanja [8]. The scientific papers of scientists and professional associations are devoted to the study of the information society, formation of new technological modes, models of electronic business, implementation of digital technologies and development of digital sharing economy: S. Asharaf [9], T. Issa [10], U. B. Vertakova [11], Boston Consulting Group [12], and also I. Belk [13,14], R. Botsman [15], A. Sundararajan [16], T. Weber [17], C. Lamberton [18], V. Mohlvann [19].

In this case, the matters of sharing economy development and digitalization are mainly considered in whole without studying their mutual interaction and mutual influence.

Study purpose is to substantiate the nature, features and characteristics of the digital sharing economy, which is based on the "blockchain" technology, and also determination of the aspects of its development in Russia. The study was performed based on materials featuring the development of this concept both in the whole world and its spread in the Russian economy.

\section{Main results of the study}

The studies of the authors $[11,20,21$, etc.] show that in the current context the set of conditions and factors of information globalization has led to the formation of new economic terms which are commonly called as the "digital economy", the formation intensity of which is different for separate countries. Big data, artificial intelligence technologies, and other digital technologies lead to high decision-making speed, forming communications with 
buyers or suppliers and control of both supply and demand. The economy has gradually diverged the conventional model of centralized organizations, where large operators, which often hold a dominant position, are responsible for rendering services to a group of passive consumers. For the first time, Lawrence Lessig, a Professor of Law at the Stanford University implemented the sharing economy concept in 2008 when he described how many Internet users significantly save while organizing a group in the network and buying the sharing things at very large discount. And by 2010, the Internet services for exchanging the services and things between individuals has been rapidly risen so that they started speaking of the sharing phenomenon everywhere [12].

Currently, the civilization is going towards a new model of increasingly decentralized organizations, where large operators are responsible for aggregating the resources of many people to provide services to a much more active group of consumers. This shift signifies the appearance of a new generation of "dematerialized" organizations which do not require physical offices, assets and even employees. The sharing economy characteristics in the age where the digitalization processes development are shown in Fig. 1.

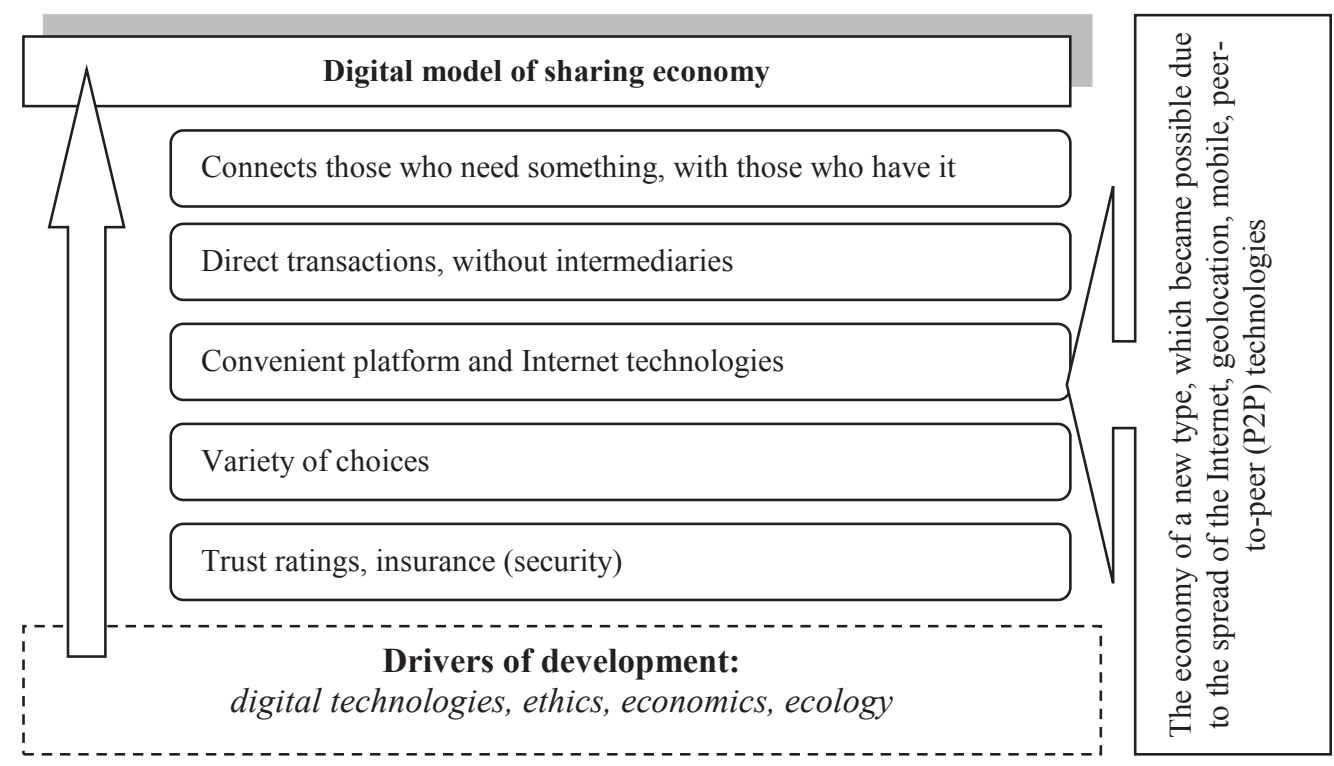

Fig. 1. Characteristics of the sharing economy (compiled by the authors).

The problem with the functioning of this model is that the value produced by the group generally is not distributed in equal shares among all those who contributed to its production; the large intermediaries managing the platforms form the profit.

To remove this imbalance, the new digital economy technology is used. The distributed registry system (Blockchain) is a special technology that is based on the platforms for operations between equal participants operating without intermediaries and in which decentralized information storage is used to reflect all transaction data. The new digital business models are aimed at reducing costs, obtaining additional revenue from digital solutions, optimizing customer interaction and improving customer service by means of studying their experience $[20,21]$.

For the first time, the "blockchain" technology was used in the financial sector, where it served as the basis for the initial creation of the digital currency "bitkoyn", and later other types of digital currencies [20]. 
Recently, there are more and more applications that expand the key function of this technology - the decentralized storage of transaction data - by means of integration of the mechanisms allowing real transactions in the decentralized manner. These mechanisms, which are called as "smart contracts", operate based on the individual rules (for example, specific requirements for quantity, quality, price), and which allow automatic selection of potential customers for suppliers and vice versa based on the distributed registries (Fig. 2).

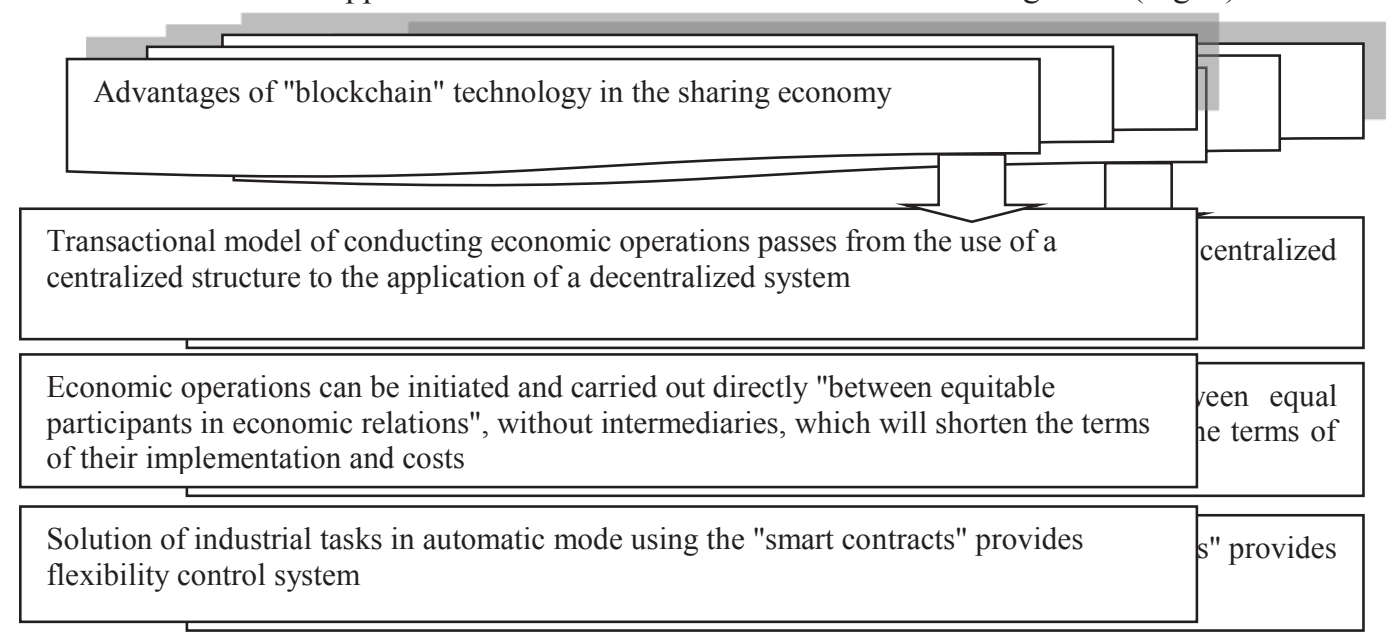

Fig. 2. Advantages of "blockchain" technology in the sharing economy (compiled by the authors).

At the same time, the following factors shall be classified as the factors that currently prevent the implementation of blockchain based applications [20]:

- lack of methodological support for regulatory and legal requirements that shall be met when implementing the blockchain-projects;

- complexity of applying the collective voice of all the parties involved in the blockchain system, in connection with the lack of the best practices;

- low operation speed;

- complexity in setting up and managing the infrastructure;

- lack of reliable and effective process solutions.

Thus, the technology itself, which ensures the sharing economy functioning, has not yet reached the necessary maturity level and continues developing. Overview of the current state of the distributed registry system and its development prospects are given in Fig. 3. 


\begin{tabular}{|c|c|c|}
\hline $\begin{array}{l}\text { PLAYERS OF THE } \\
\text { WORLD MARKET }\end{array}$ & $\begin{array}{l}\text { PILOT PROJECTS WITH } \\
\text { BLOCKCHAIN IN THE } \\
\text { RUSSIAN FEDERATION }\end{array}$ & $\begin{array}{c}\text { THE VOLUME OF THE WORLD } \\
\text { MARKET OF BLOCKCHAIN- } \\
\text { TECHNOLOGIES, } \\
\text { CRYPTOCURRENCIES AND } \\
\text { DIGITAL ASSETS } \\
\text { (billion \$) }\end{array}$ \\
\hline Microsoft & $\mathrm{CB}$ & $2016-49$ \\
\hline Deloitte & VEB & \\
\hline IBM & Sberbank & Prediction \\
\hline Linux Foundation & VTB & $2018-143$ \\
\hline Chain Inc. & & $2020-230$ \\
\hline Circle Internet Financial & Alfa Bank & \\
\hline $\begin{array}{l}\text { Ripple } \\
\text { Ethereum }\end{array}$ & FAS & \\
\hline $\begin{array}{l}\text { RUSSIAN MARKET } \\
\text { PLAYERS }\end{array}$ & $\begin{array}{c}\text { INTEREST TO } \\
\text { BLOCKCHAIN IN THE } \\
\text { RUSSIAN FEDERATION }\end{array}$ & \\
\hline Qiwi & FTS & \\
\hline Financial Cryptography & ROSREESTR & \\
\hline Waves Platform & Government of Moscow & \\
\hline FinTech Association & $\begin{array}{l}\text { Government of the Republic } \\
\text { of Tatarstan }\end{array}$ & \\
\hline
\end{tabular}

Source: prepared by the authors according to the data of IDS Worldwide Semiannual Blockchain Spending Guide, 2017 [22, 23]

Fig. 3. The current state of the distributed registry system.

The blockchain technology can principally change the economic system to which we are accustomed, first by transforming individual sectors, and ultimately through the transforming the entire digital market.

This technology is truly effective in those systems where full data synchronization and confirmation of authorship of the performed actions are required. The "blockchain" technology innovation is the transactions information is no longer stored in the centralized database, but transferred to the computers of all network members who store data locally. The "Bitcoin" application was the first application based on the blockchain technology for so-called crypto currency (bitcoin). In recent years the bitkoyne has served as the basis for creation of other blockchain applications, most of which are currently being developed in the financial sector. More recently a number of companies have been created and some projects have been launched, the purpose of which is to apply the blockchain principles in other industries.

The blockchain was created as a niche product in secondary markets, but recently this technology has attracted the attention of experts from different industries, and also caused the increased interest from the media side. However, many specialists and managers of state and private organizations are not sure what measures they shall take based on this trend [20].

The transactional model based on the blockchain technology reflecting the procedures of the transactions in the economic system is shown in Fig. 4. 


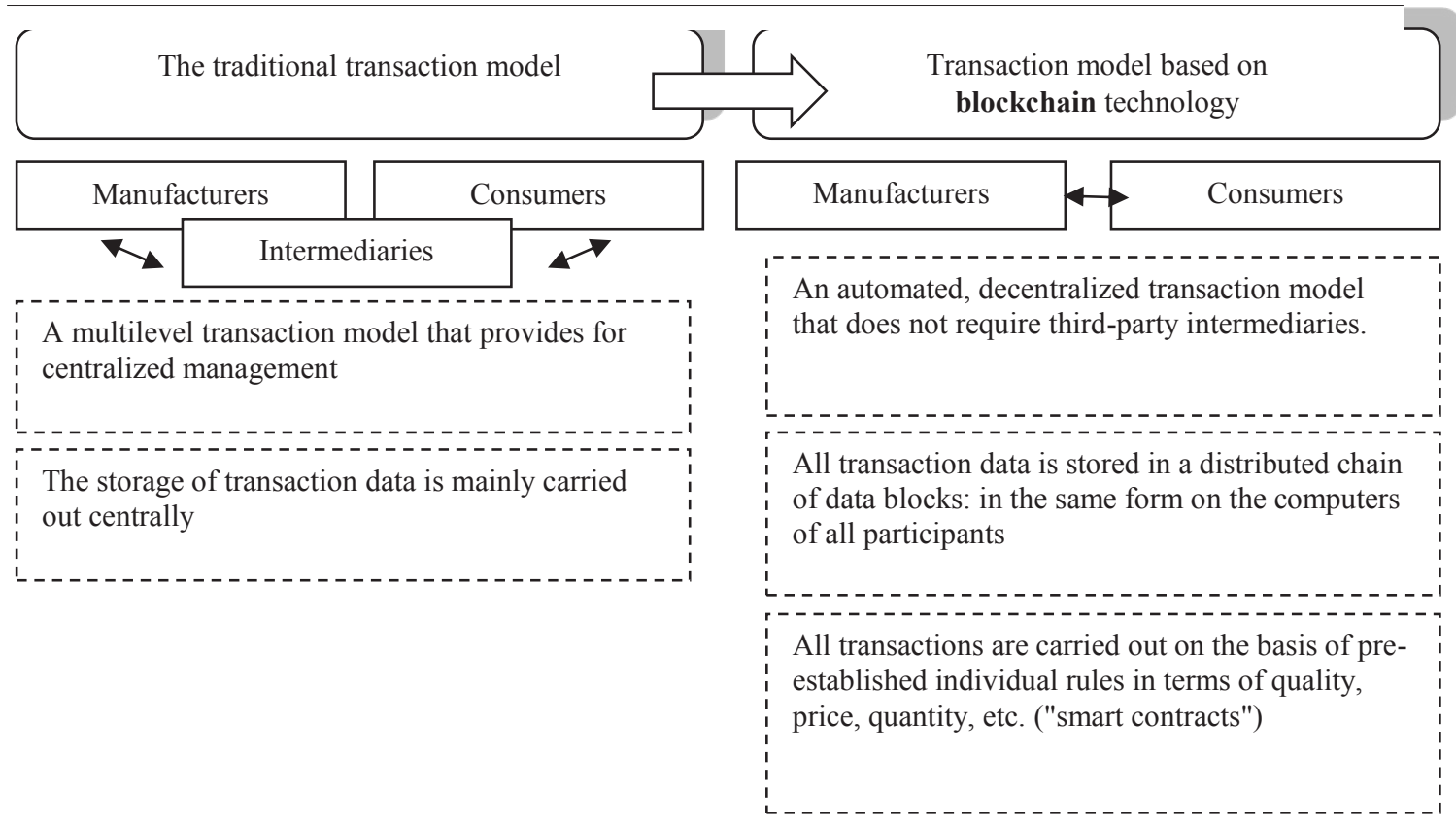

Fig. 4. Transactional model based on blockchain technology.

Now the digitalization has become an irreversible process, the most important factor for development of almost any industry. In modern terms, the innovation driver is not only the state or large social and industrial groups. The transition is formed through the consumer sector, which concentrates the innovative approaches and practices of the digital economy due to its mobility and the ability to accumulate capital [21]. The adaptability of the digital environment makes it possible to optimize the business processes in the most complex management models. The business task is to be properly integrated into these terms of the sharing economy and its prospects. The vector of sharing economy development is given in Fig. 5.

The sharing economy fields are quite wide:

1) financial

- trade in digital securities (confirmation of a share and transfer of ownership);

- currency exchange / conversion;

- housing and utilities sector;

- data storage;

- transactions between equal participants of the network;

- etc.

2) non-financial:

- protection of personal information of the consumers;

- confirmation of ownership rights;

- network infrastructure;

- etc. 

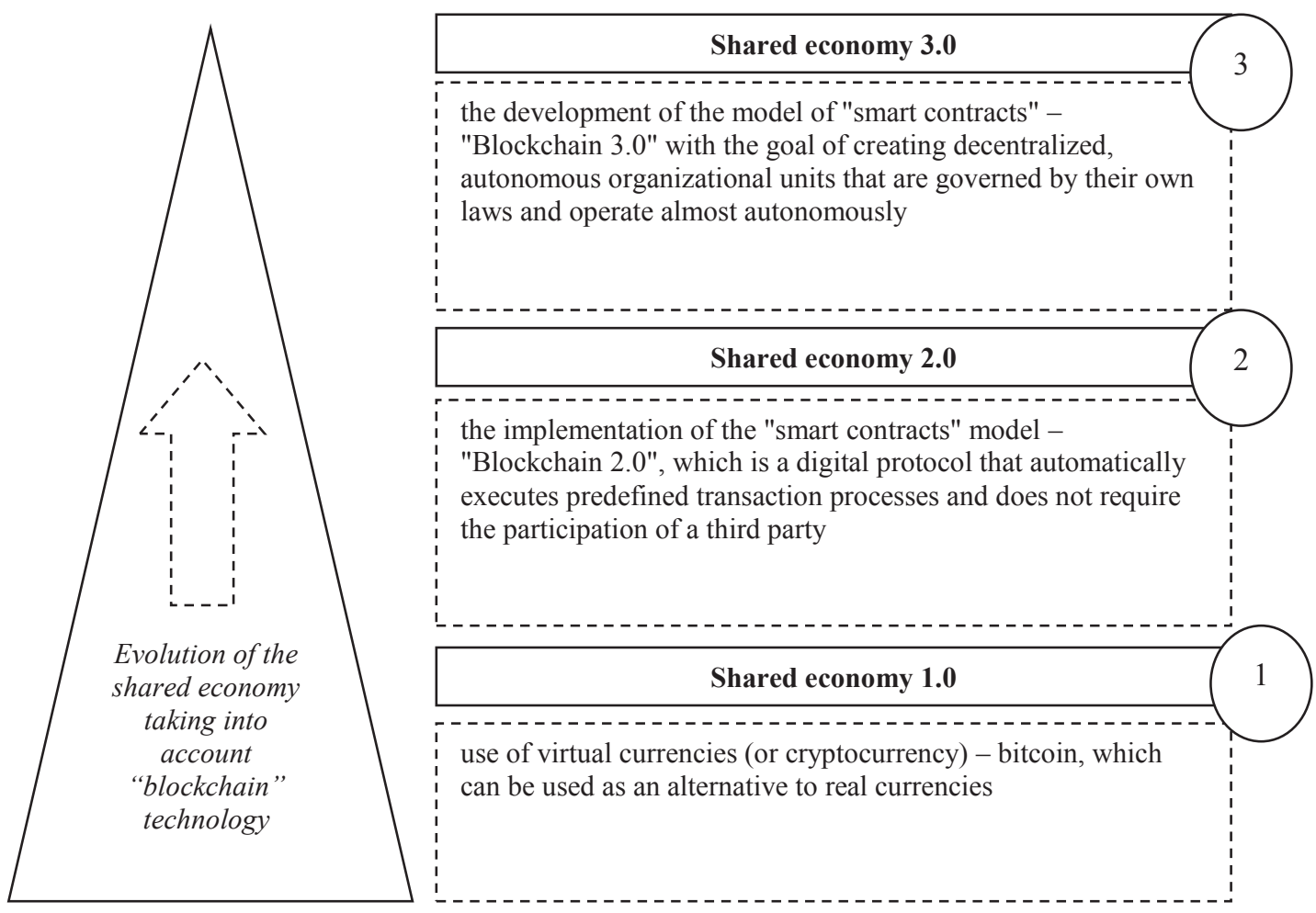

Fig. 5. The author's vision of the development of the shared economy, taking into account the "blockchain" technology.

This technology and various solutions on its basis have made significant progress, since the first blockchain-application "Bitcoin" was launched in 2009. Currently, two most important digital aspects in the financial field can be noted [21]:

- the tendency for creation of "smart contracts" applications based on the blockchain technology;

- programs for formation of closed chains of blocks.

We think that the scope of potential blockchain applications in the sharing economy due to these trends and programs.

The fundamental elements of the decentralized system of sharing economy are the following:

- transactions (selection of a suitable consumer/manufacturer) are carried out either fully automatically (based on the "smart contracts") or manually;

- transactions are reflected in the chain of blocks with the protection against extraneous interference;

- payments using crypto currency.

The authors indicated the following capabilities for using the "blockchain" technology by the Russian business in the time of digital economy:

- decentralized storage of transactions data to improve their protection level and to ensure the higher autonomy level from a single body that performs central administration; 
- using the blocks chain to facilitate payments with crypto currencies, contracts digitization, digital content management, transactions verification, and trading operations performance.

The following branches: finance, investment, public sector, trading, health care, energy are the prospective for implementation and development of blockchain technologies in Russia.

The main aspects of subsequent proactive implementation of "blockchain" technologies into the digital model of sharing economy can be:

- issue of digital state currencies based on the blockchain;

- increase of a smart contracts share in the total volume of contracts up to $10 \%$;

- full transfer of registers (recording of rights to real estate, registration of birth, marriage, death) to the "blockchain" technology;

- opening of the first sections of roads where autonomous cars driving will be performed through the blockchain;

- exchange of medical records between medical institutions based on the blockchain.

Thus, not only technologies but also new models for management of technologies and data become an important factor of success in the highly competitive and trans-border digital model of sharing economy, allowing for rapid response and modeling of subsequent challenges and problems.

The most difficult task that "blockchain" technology poses under development of the digital model of sharing economy is how to integrate the social concept, where there is no follow-up mechanism, into the sociotechnical system. These follow-up mechanisms appeared in the social concepts as a result of evolutionary cultural development. They led to the creation of a whole number of interrelated systems, each of which to a certain extent has the ability to adapt when it is necessary to deal with the improper or malicious behavior of individual participants. These interrelated systems can temporarily exclude participants and reintegrate them in case of correction, for example, using the social concept of forgiveness.

Social systems based on such collective interaction are relatively stable, true and fair. In contrast, process systems are based on deterministic, isolated concepts providing the adoption of operational decisions that can have serious consequences for individual participants. The digital economy is interfaced with the high-hume and high-tech epochs, that is, high humanitarian and technical technologies [12].

In order to create a carefully developed concept in terms of technology and to ensure that the potential benefits offered by the decentralized structure can be fully used, it will be necessary to implement the training procedure and continuous adjustment system based on the formation of a competence-based personnel model.

At the stage of development of the digital model of sharing economy, in the absence of sufficient practice to assess the practicability of implementing the certain restrictive measures, the restrictive regulation can lead to hindering the development of the new technological generation economy and, accordingly, to delaying Russia behind the leading economies of the world in modernization of traditional manufacturing industries and industries services, as well as modernization of management procedures. In this regard, in the nearest future, it is advisable to observe the non prohibitive legal regulation in this area. The legal regulation of the digital economy institutions shall be firstly aimed at providing the necessary conditions for their development including support for innovative developments, and to promote the technologies implementation and development including the "blockchain" technology.

Thus, the authors:

1. Showed that the new consumption economy model under the conditions of shared use of digitalization, big data concept, cyberphysical systems, Internet of things, etc., opens the global opportunities for effective development. Building the processes of interaction among 
all digitalization participants will allow the business structures to combine the potential opportunities, harmonize process interests, and to reduce the risk level. And as a consequence, this will help to increase the level of their innovative activity and to create the prospecting base for the further economy development.

2. The features are reflected and the sharing economy characteristic is presented under the digitalization conditions.

3. The content, advantages, current state and prospects of the blockchain technology development are presented.

4. A transactional model of the economic system based on the blockchain technology is presented.

\section{Conclusions}

Mainstreaming of the "blockchain" technology with observance of all the laid principles will fundamentally change the way how the economy functions today and how financial transactions are carried out. The article specifies that the blockchain was developed to create a decentralized model for data exchange and storage, which is controlled with the decentralized operating system. The decentralized systems can not be controlled by a minority of participants or a single body that is responsible for the central management, and they are transparent for all participants, as well as self-controlled. The authors conclude that the "blockchain" technology allows creating a self-regulating and self-controlling sharing economy, in which transactions are performed through fulfilling digital contracts. This kind of decentralized management can lead to reduction in a number of inefficient operations and decreasing in the corruption level. Due to the fact that each individual network element processes each transaction, none of the elements control the database as a whole. From this point of view, decentralization also plays the role both in increasing the level of security and sustainability of the economic system.

The digital model of sharing economy provides free operations on own terms. This opens the prospects for development of innovative intermediary services in the future. Such services could allow a third party to approve or reject a transaction in case of disagreement between other parties that requires subsequent development of both regulatory and methodological support.

\section{References}

1. On approval of the program "Digital Economy of the Russian Federation". Regulation of the government of the Russian Federation No 1632 dated 28.07.2017. [online], Available at: http://base.consultant.ru (2017)

2. A. V. Babkin, D. D. Burkaltseva, D. G. Kosten, Yu. N. Vorobyov, Scientific and technical reports of the St. Petersburg State Polytechnic University. Economics, 10(3) (2017)

3. On the Digital Economy of China. [online], Available at: http:// vsesovetnik.ru/archives/2205527.02.17 (2017)

4. Strategy for the development of the EAEU digital space, 2025. [online], Available at: http://d-russia.ru/wp-content/uploads/2016/10/strategy.pdf (2016)

5. In Japan the crypto currency has become an official means of payment. [online], Available at: http://www.rosbalt.ru/business/2017/04/01/1603901.html (2017)

6. D. Tapscott, The electronic digital society: Pros and cons of the network intelligence epoch (Kiev: INT Press; Moscow: Relf bull.1999) 
7. A. Stephany, The Business of Sharing: Making it in the New Sharing Economy (Springer, 2015)

9. U. Huws, Labor in the Global Digital Economy: The Cybertariat Comes of Age. (NYU Press, New York, 2014)

8. M. Vidas-Bubanja, I. Bubanja, 39th International Convention on Information and Communication Technology, Electronics and Microelectronics (2016)

9. S. Asharaf, S. Adarsh, Decentralized Computing Using Blockchain Technologies and Smart Contracts: Emerging Research and Opportunities. (IRMA, Hershey: PA, USA: IGI Global 2017).

10. T. Issa, P. Kommers, Th. Issa, P. Isaías, Smart Technology Applications in Business Environments. (IRMA, Hershey: PA, USA: IGI Global 2017)

11. Yu. V. Vertakova, T. O. Tolstykh, E. V. Shkarupeta, V. V. Dmitrieva, Transformation of management systems under the economy digitalization impact. (Iugo-zapadnyi gos. un-t, Kursk, 2017)

12. World Development Report, 2016. Digital dividends. Overview. International Bank for Reconstruction and Development / World Bank. [online], Available at: http://wwwwds.worldbank.org/external/default/WDSContentServer/IB/2016/.pdf (2016)

13. R. Belk, Annals of the American Academy of Political and Social Science, 611 (2007)

14. R. Belk, Cambridge Journal of Regions Economy and Society, 10 (2017)

15. R. Botsman, R. Rogers, What's Mine Is Yours: The Rise of Collaborative Consumption (Harper Business, New York 2010)

16. A. Sundararajan, The Sharing Economy: The End of Employment and the Rise of CrowdBased Capitalism. (MIT Press, Cambridge 2016).

17. T. A. Weber, Journal of Management Information Systems, 31 (2014)

18. C. P Lamberton, R. L. Rose, Journal of Marketing, 76 (2012)

19. M. Mohlmann, Journal of Consumer Behavior, 14 (2015)

20. A. V. Babkin, D. D. Burkaltseva, V. V. Pshenichnikov, A. S. Tyulin, Scientific and technical reports of the St. Petersburg State Polytechnic University. Economics. 10(5) (2017) DOI: 10.18721/JE.10501

21. A. A. Aletdinova, et al. Digital transformation of economy and industry: problems and prospects. (Publishing House of Polytechnic University, Saint Petersburg, 2017) DOI 10.18720 / IEP/2017.4

22. IDACB: The market of crypto currency and blockchain technology increases 20 times larger. [online], Available at: https://www.if24.ru/rynok-kriptovalyut-vyros-v-20-raz/ (2018)

23. World Summit of Blockchain and Crypto-Currency. [online], Available at: http://blockchainhouse.media/vsemirnyj-sammit-blokchejna-i-kriptovalyut/ (2018) 